\title{
THE ASSOCIATION BETWEEN KNOWLEDGE AND ATTITUDE, IN REPRODUCTIVE HEALTH AND SEXUAL BEHAVIOR IN FEMALE ADOLESCENTS, BANDA ACEH
}

\author{
Sofia ${ }^{1}$, Rianda Akmal2), Rajuddin3) \\ 1)Department of Environmental Health, Faculty of Medicine, \\ Universitas Syiah Kuala \\ 2)Faculty of Medicine, Universitas Syiah Kuala \\ 3)Department Obstetrics and Gynecology, Faculty of Medicine, \\ Universitas Syiah Kuala
}

\begin{abstract}
Background: More than a quarter of the world's population is between the ages of 10 and 24, with 86\% living in less developed countries. These young people are tomorrow's parents. Reproductive health is important for adolescents. The reproductive and sexual health decisions they make today will affect the health and well-being of their communities and of their countries for decades to come. Lack of knowledge about reproductive health in adolescents can make them easily influenced by misinformation that is harmful to their reproductive health. This study aimed to determine the association between knowledge, attitude, and healthy sexual behavior among female high school students in Banda Aceh.

Subjects and Method: This was a cross-sectional study conducted at senior high school 8, Banda Aceh, Indonesia, in March 2012. A sample of 145 female students was selected for this study by stratified random sampling. The dependent variable was healthy sexual behavior. The independent variables were knowledge and attitude about reproductive health. The data were collected by questionnaire and analyzed by Chi-square test.

Results: $58.62 \%$ female students had good knowledge and $65.52 \%$ had positive attitude. Healthy sexual behavior increased with good knowledge $(\mathrm{OR}=1.76 ; 95 \%$ $\mathrm{CI}=0.51$ to $0.67 ; \mathrm{p}=0.147)$ and positive attitude about reproductive health $(\mathrm{OR}=$ $2.00 ; 95 \% \mathrm{CI}=0.58$ to $0.73 ; \mathrm{p}=0.078$ ).

Conclusion: Healthy sexual behavior is associated with knowledge and attitude about reproductive health. Therefore, health education plays an important role in increasing their knowledge and behavior of young people in order to maintain good reproductive health.
\end{abstract}

Keywords: sexual behaviour, attitude, knowledge, reproductive health, female adolescents

\section{Correspondence:}

Sofia. Department of Environmental Health, Faculty of Medicine, Universitas Syiah Kuala, Jl. Teuku Nyak Arief, Darussalam 23111, Banda Aceh, Indonesia. Email: sofia@unsyiah.ac.id. Mobile: +628126993145. 